\title{
Phospholipid content of bronchoalveolar lavage fluid in granite workers with silicosis in Quebec
}

\author{
R Bégin, O Lesur, T Bouhadiba, L Guojian, P Larivée, B Melloni, M Martel, A Cantin
}

\begin{abstract}
Background-Some of the prominent features of silicosis are hyperplasia and hypertrophy of epithelial type II cells, which in experimental animals are often accompanied by accumulation of phospholipids in the lung.

Methods-The total phospholipid content of lung lavage fluid and its composition in 28 granite stone cutters with long term exposure to silica dust (23 with radiological silicosis) was compared with that of lavage fluid in 15 normal volunteers, 15 patients with untreated idiopathic pulmonary fibrosis, and 19 patients with untreated stage 2 or 3 sarcoidosis. All lavage fluid was obtained at the time of first pulmonary investigation, which also included lung function tests.
\end{abstract}

Results-In the normal subjects total phospholipid content was $1.13(0 \cdot 16) \mu \mathrm{g}$ phosphorus/ml of lung lavage, in the patients with idiopathic pulmonary fibrosis $0.52(0.07) \mu \mathrm{g} / \mathrm{ml}(p<0.05)$, and in the patients with sarcoidosis 1.02 $(0 \cdot 20) \mu \mathrm{g} / \mathrm{ml}$ composition being in the range reported in humans. In the patients with silicosis total phospholipid content was significantly decreased to an average of $0.46(0.08) \mu \mathrm{g} / \mathrm{ml}$ compared with the findings in normal subjects and patients with sarcoidosis. Within the group exposed to silica changes in total phospholipid content did not correlate with the severity of the radiographic disease, changes in lung function, the cellularity of lung lavage fluid, or hyaluronate concentrations. The secretory capacity of rat epithelial type II cells was not significantly different when cultured with bronchoalveolar lavage fluid from all four groups of subjects.

Conclusions-Total phospholipid content in lung lavage fluid was significantly reduced in granite workers with radiological evidence of lung disease, but showed no correlation with radiological or functional markers of disease severity.

(Thorax 1993;48:840-844)

Reductions in the amount and composition of surface active materials in alveolar lining fluids have been observed in the adult res- piratory distress syndrome ${ }^{1}$ and idiopathic pulmonary fibrosis. ${ }^{23}$ These observations contrast with results in animals with experimental acute lung injury-for example, with silica ${ }^{4}$-in which the total phospholipid content of bronchoalveolar lavage fluid is usually increased.

In humans the accumulation of phospholipids in the lung is part of the repair process following silica inhalation, ${ }^{67}$ being found in the acute form of silicoproteinosis or in the nodular form of the disease ${ }^{8}$ associated with increased numbers of epithelial type II cells in the lavage fluid. ${ }^{9}$

Other aspects of silicosis in humans have been studied. Subclinical alveolitis has been reported in granite workers, characterised by excessive accumulation of lymphocytes and immunoglobulins and associated with normal phagocytic function and viability of dust laden alveolar macrophages. ${ }^{111}$ The subclinical alveolitis was associated with inhibitory activity of lung lavage fluid against fibroblast proliferation, but fluid from patients with the alveolitis of simple or confluent silicosis upregulated the growth of fibroblasts. ${ }^{12} \mathrm{We}$ have documented a direct proliferative action of silica on type II cells ${ }^{13}$ and observed a proliferative activity for type II cells in the bronchoalveolar lavage fluid from normal human lung. ${ }^{14}$ This activity was further upregulated early in the silicotic process ${ }^{14}$ in contrast to the fibrosing activity, which is increased only after clinical disease is detected. ${ }^{12}$

We measured the phospholipid content of lung lavage fluid in humans exposed to silica, comparing the findings with those in normal subjects and patients with idiopathic pul- N monary fibrosis or sarcoidosis and correlating the findings with functional markers of severity of disease. We also tested a possible mechanism for the regulation of the accumulation of phospholipids in lavage fluid and evaluated the capacity of fluid from controls and patients with idiopathic pulmonary fibrosis to induce the secretion of phospholipids and proliferation of type II rat epithelial cells.

\section{Methods}

PATIENTS

The 15 normal subjects were paid volunteers who were free of symptoms and disease. The 15 patients with idiopathic pulmonary fibrosis and the 19 patients with sarcoidosis were 
diagnosed on the basis of established criteria. ${ }^{1516}$ At the time of investigation all patients with idiopathic pulmonary fibrosis and with sarcoidosis had had the disease for less than one year, as determined by the patients' symptoms. The 28 cases of silicosis were in men exposed in the granite cutting industry of the eastern townships of Quebec for an average of 30 years (range 18-35). They had no history of other pulmonary diseases. The granite industry of the eastern townships of Quebec has been characterised. ${ }^{12}$ In the patients with silicosis the disease was symptomatic in most cases and investigation was carried out at the time of the first abnormal results in a chest radiograph for the cases of simple silicosis and at the time of recognition of large opacities for the cases of confluent silicosis. All patients and subjects had been non-smokers for at least two years before investigation. The study was approved by the ethical committee of our hospital and written informed consent was obtained from each subject.

\section{LUNG FUNCTION TESTS}

All patients underwent pulmonary function tests including lung volumes, single breath carbon monoxide diffusion capacity, gas exchange at rest and after exercise, and lung compliance as previously described. ${ }^{15} 16$

\section{BRONCHOALVEOLAR LAVAGE}

Bronchoalveolar lavage was performed in each subject as previously described. ${ }^{15}$ The albumin concentration in the lavage fluid was determined by laser nephelometry (Behring LN modular system, Hoechst Behring, Frankfurt, Germany). Lactate dehydrogenase activity was measured as a marker of nonspecific cell damage. ${ }^{13}$ An aliquot of the cell free supernatant of the lavage fluid was used for the assay of hyaluronate concentrations according to the technique of Laurent and Tengblad. ${ }^{17}$

Phospholipids were extracted from a $3 \mathrm{ml}$ sample of supernatant in $10 \mathrm{vol}$ chloroform/ methanol solvent $(2: 1)$ and collected according to the method of Folch et al. ${ }^{18}$ The lower chloroform layer was evaporated to dryness and suspended in a small volume of chloroform. Total phospholipid concentration was measured by the method of Bartlett. ${ }^{19}$ Individual phospholipids were separated by thin layer chromatography on silica gel $\mathrm{H}$ plates (Merck Chemical Company,

Table 1 Mean (SE) results of lung function tests

\begin{tabular}{lllll}
\hline & \multicolumn{3}{l}{ Patients with: } \\
\cline { 3 - 5 } & $\begin{array}{l}\text { Normal } \\
\text { subjects } \\
(n=15)\end{array}$ & $\begin{array}{l}\text { Silicosis } \\
(n=28)\end{array}$ & $\begin{array}{l}\text { Idiopathic } \\
\text { fibrosis } \\
(n=15)\end{array}$ & $\begin{array}{l}\text { Sarcoidosis } \\
(n=19)\end{array}$ \\
\hline Total lung capacity (\% predicted) & $108(3)$ & $104(4)$ & $75(5)^{\star}$ & $89(4)^{\star}$ \\
Vital capacity (\% predicted) & $112(3)$ & $100(5)$ & $80(6)^{\star}$ & $94(4)$ \\
Diffusion capacity (\% predicted) & $107(5)$ & $99(10)$ & $61(6)^{\star}$ & $86(4)$ \\
Static lung compliance (\% predicted) & $103(6)$ & $89(9)$ & $36(6)^{\star}$ & $51(5)^{\star}$ \\
Resting arterial oxygen tension (torr) & $92(3)$ & $79(3)^{\star}$ & $70(4)^{\star}$ & $81(2)$ \\
\hline
\end{tabular}

${ }^{\star} \mathrm{p}<0.05$ compared with normal subjects.
Montreal) using a mixture of chloroform, ethanol, water and triethylamine (30:34:8:35). The lipids were detected under ultraviolet light after being sprayed with rhodamine. Phosphorus was estimated on gel scrapings by the method of Rouser et al. ${ }^{20}$

TYPE II EPITHELIAL CELL STUDIES

Pneumocytes from fetal rats were obtained as reported. ${ }^{13}$ The secretion of phosphatidylcholine by type II cells was evaluated by determining the release of tritiated phosphatidylcholine. The growth effect of bronchoalveolar lavage fluid on rat epithelial type II cells in vitro was evaluated by the incorporation of tritiated thymidine into type II epithelial cells at 24 hours and counting the monolayers at 48 hours, given the phase lag between DNA synthesis and cell proliferation. ${ }^{13} 14$

For these studies bronchoalveolar lavage fluid (10 ml of acellular supernatant) was concentrated by 48 hours of lyophilisation (Greeze mobile 24, Virtis, Gardines, New York) with subsequent resolubilisation and application to G25 chromatography columns (PD10, Pharmacia Canada, Baie D'Urfé, Quebec) previously saturated with Eagles minimum essential medium (Gibco, Grand Island, New York) to obtain a resulting volume 10 times the original effluent concentration in lavage fluid. ${ }^{14}$ Dilutions to $20 \%$ of the concentrated volumes of lavage fluid for normal subjects and patients with idiopathic pulmonary fibrosis were also tested. The procedures were controlled by total protein determination each time. ${ }^{14}$

\section{STATISTICAL ANALYSIS}

Data are means (SE). Statistical significance was evaluated with an analysis of variance with an $a$ of 0.05 and a $\beta$ of 0.20 (power $0 \cdot 80$ ) and a Dunnett $t$ test for comparison with control data. Relations were tested by the Spearman procedure. ${ }^{22}$

\section{Results}

LUNG FUNCTION TESTS

Table 1 shows the results of lung function tests for each group. The most severe changes were in patients with idiopathic pulmonary fibrosis and the least in patients with silicosis, which included five cases of long term exposure with normal results in chest radiographs, 14 cases of simple silicosis, and nine cases of confluent silicosis. Within the silicosis group patients with more severe radiological disease had more loss of lung function. The sarcoidosis group had lung function changes intermediate between the idiopathic pulmonary fibrosis and the silicosis group.

\section{ANALYSES OF LUNG LAVAGE FLUID}

Table 2 shows the content of bronchoalveolar lavage fluid. All groups of patients had significantly increased cellularity, with changes in the subsets of cells as in previous reports. ${ }^{12}$ Albumin, lactate dehydrogenase, and hyaluronate concentrations were increased in all 


\begin{tabular}{|c|c|c|c|c|}
\hline & \multirow[b]{2}{*}{$\begin{array}{l}\text { Normal subjects } \\
(n=15)\end{array}$} & \multicolumn{3}{|l|}{ Patients with: } \\
\hline & & $\begin{array}{l}\text { Silicosis } \\
(n=28)\end{array}$ & $\begin{array}{l}\text { Idiopathic fibrosis } \\
(n=15)\end{array}$ & $\begin{array}{l}\text { Sarcoidosis } \\
(n=19)\end{array}$ \\
\hline Total cells $\left(1 \times 10^{4} / \mathrm{ml}\right)$ & $12 \cdot 6(1 \cdot 2)$ & $28 \cdot 0(5 \cdot 1)^{\star}$ & $35 \cdot 3(4 \cdot 6)^{\star}$ & $30 \cdot 1(4 \cdot 1)^{\star}$ \\
\hline Macrophages: $1 \times 10^{4} / \mathrm{ml}$ & $8.99(1 \cdot 1)$ & $21 \cdot 8(4 \cdot 5)^{\star}$ & $23.9(2 \cdot 6)^{\star}$ & $16 \cdot 1(2 \cdot 2)$ \\
\hline$\%$ & $69 \cdot 1(2 \cdot 3)$ & $78 \cdot 2(4 \cdot 1)$ & $71 \cdot 3(3 \cdot 9)$ & $55 \cdot 8(2 \cdot 7)^{\star}$ \\
\hline Lymphocytes: $1 \times 10^{4} / \mathrm{ml}$ & $3.4(0.2)$ & $4 \cdot 7(1 \cdot 4)$ & $8 \cdot 6(2 \cdot 9)$ & $10 \cdot 5(1 \cdot 6)^{\star}$ \\
\hline$\%$ & $28 \cdot 1(2 \cdot 1)$ & $17 \cdot 8(3 \cdot 6)$ & $20 \cdot 7(4 \cdot 1)$ & $36 \cdot 0(3 \cdot 2)$ \\
\hline Neutrophils: $1 \times 10^{4} \mathrm{ml}$ & $0.3(0.07)$ & $0.8(0.7)$ & $1 \cdot 77(0 \cdot 6)$ & $2 \cdot 7(1 \cdot 3)$ \\
\hline$\%$ & $1.7(0.4)$ & $2 \cdot 2(1 \cdot 2)$ & $4 \cdot 6(1 \cdot 2)$ & $6 \cdot 1(2 \cdot 9)$ \\
\hline Albumin $(\mu \mathrm{g} / \mathrm{ml})$ & $33 \cdot 1(2 \cdot 7)$ & $74 \cdot 0(15 \cdot 7)$ & $121.9(35.4)^{\star}$ & $98.4(23.4)$ \\
\hline Lactate dehydrogenase $(\mathrm{mU} / \mathrm{ml})$ & $3.0(0.9)$ & $13 \cdot 3(2 \cdot 8)^{\star}$ & $9 \cdot 4(2 \cdot 3)$ & $11 \cdot 1(2 \cdot 9)$ \\
\hline Hyaluronate (ng/ml) & $45(11)$ & $57(16)$ & $126(37)^{\star}$ & $144(54)^{\star}$ \\
\hline Total phosphorus $(\mu \mathrm{g} / \mathrm{ml})$ & $1 \cdot 13(0 \cdot 16)$ & $0.47(0.08)^{\star}$ & $0.52(0.07)^{\star}$ & $1.02(0 \cdot 20)$ \\
\hline \multicolumn{5}{|l|}{ Phospholipids(\%) } \\
\hline Phosphatidylcholine (PC) & $58 \cdot 8(3 \cdot 2)$ & $51 \cdot 3(4 \cdot 5)$ & $53 \cdot 9(4 \cdot 2)$ & $50 \cdot 1(4 \cdot 0)$ \\
\hline Phosphatidylglycerol (PG) & $27 \cdot 4(3 \cdot 9)$ & $25 \cdot 3(4 \cdot 9)$ & $22 \cdot 0(1 \cdot 9)$ & $30 \cdot 0(5 \cdot 0)$ \\
\hline \multicolumn{5}{|l|}{ Phosphatidylinositol (PI) } \\
\hline Phosphatidylserine (PS) & $3.4(0.3)$ & $4 \cdot 2(0 \cdot 6)$ & $6.9(1.6)$ & $5 \cdot 8(1 \cdot 0)$ \\
\hline Phosphatidylethanolamine & $5.6(0.9)$ & $13.4(1.4)^{\star}$ & $10 \cdot 2(1 \cdot 6)$ & $6 \cdot 2(1 \cdot 4)$ \\
\hline Sphingomyelin & $2 \cdot 5(0.2)$ & $2.6(0.4)$ & $3.5(0.8)$ & $4 \cdot 1(1 \cdot 0)$ \\
\hline Lysophosphatidylcholine & $2 \cdot 2(0 \cdot 1)$ & $2.9(0.6)$ & $3.5(0.8)$ & $3.0(0.9)$ \\
\hline $\mathrm{PG} / \mathrm{PC}$ ratio & $0.49(0.09)$ & $0.57(0.18)$ & $0.43(0.07)$ & $0.65(0.19)$ \\
\hline PG/PI + PS ratio & $8 \cdot 2(0.9)$ & $6 \cdot 3(1 \cdot 1)$ & $3.9(0.9)$ & $6 \cdot 4(2 \cdot 2)$ \\
\hline
\end{tabular}

${ }^{\star} \mathrm{p}<0.05$ compared with normal subjects.

groups of patients, with significant increases for albumin concentration in the idiopathic pulmonary fibrosis group alone, for lactate dehydrogenase concentration in the silicosis group, and for hyaluronate concentration in the idiopathic pulmonary fibrosis and sarcoidosis groups (table 2).

The content of phospholipids in the lavage fluid is also shown in table 2 and the figure. Total phosphorus concentration was significantly decreased in the lavage fluid of the silicosis and idiopathic pulmonary fibrosis groups but was not significantly different from normal subjects in the sarcoidosis group. On an individual basis for the total population of the study or within each group, these changes in phosphorus content were not significantly related to markers of cellularity or biochemical analyses (table 2), or to the severity of disease as determined by lung function. Within the silicosis group the subsets of subjects with simple and confluent silicosis had lower values than the subset of patients exposed to silica but without radiological silicosis (fig).

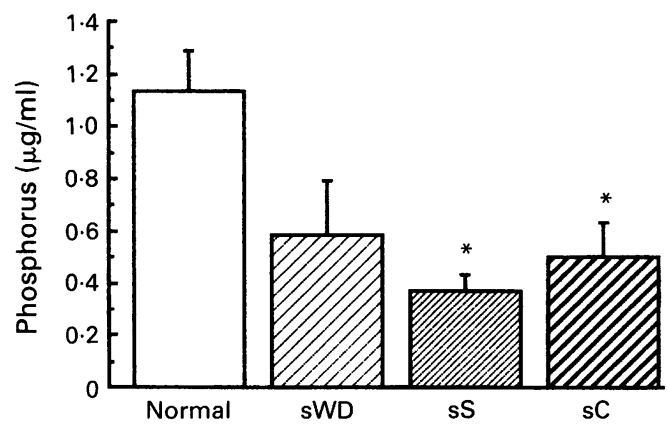

Mean (SE) total phospholipid concentrations in lung lavage fluid. All lavage fluid was obtained comparatively early in the course of disease, at time of initial consultation except in patients with confluent silicosis who had lavage at time of consultation for confluence of opacities. Patients with silicosis are grouped in subsets without radiological disease ( $s W D, n=5$ ), with simple silicosis ( $s, n=14$ ), and with confluent silicosis (sC, $n=9) ;{ }^{*} p<0.05$ compared with normal subjects.
TYPE II EPITHELIAL CELL SECRETION AND PROLIFERATION

The terbutaline stimulated secretion of tritiated phosphatidylcholine by the epithelial type II cell in culture was $19 \%(0.6 \%)$ in control conditions and was unaffected by the presence of lavage fluid from normal subjects or patients with silicosis, idiopathic pulmonary fibrosis, or sarcoidosis.

The thymidine incorporation by rat epithelial type II cells after culture with lavage fluid concentrate remained at the control level for the normal and the idiopathic pulmonary fibrosis groups. Dilution of the fluid from patients with idiopathic pulmonary fibrosis did not affect the proliferation activity of rat type II epithelial cells. The results in thymidine uptake were paralleled by the cell counts.

\section{Discussion}

We have confirmed previous reports in patients with idiopathic pulmonary fibrosis of low total phospholipid concentrations in $N$ bronchoalveolar lavage fluid compared with normal subjects and patients with sarcoidosis. ${ }^{23}$ Robinson et $a l^{2}$ and Hughes et $a l^{\beta}$ found proportionate reductions in phosphatidylglycerol, which we did not confirm. In agreement with Robinson et al we did not find a significant relation for cellular components and phospholipids of lavage fluid or a significant relation between pulmonary function test variables of disease severity and the concentrations of phospholipid in lavage fluid. Furthermore in our patients with idiopathic pulmonary fibrosis there was no effect of lavage fluid on the secretion or proliferation of epithelial type II cells, which contrasts with the effect of lavage fluid of patients with idiopathic pulmonary fibrosis on the proliferation of fibroblasts. ${ }^{15}$

In silicosis we observed significant decreases in the total phospholipid content of 
lavage fluid, which contrasts with results in animal experiments. ${ }^{45}$ Several factors can explain these differences. Firstly, the animal models will clearly always be imperfect as type, mode, and intensity of exposure, work environment, and biological substratum can only be approximated. ${ }^{7}$ Secondly, in sheep the high concentrations of phospholipids in lavage fluid are at least partially sustained by the biologically active silica particles in the bronchoalveolar milieu ${ }^{23-25}$; the reduction over time of the active dust load ${ }^{25}$ may contribute to the reduction of phospholipid accumulation. Finally, our patients with radiographic silicosis had been retired for several months before this study, which would also contribute to the reduction in the phospholipid concentration of the bronchoalveolar fluid.

To explain the reduction in the phospholipid content in bronchoalveolar lavage fluid of our patients with silicosis possible mechanisms of regulation of the levels of phospholipids in the bronchoalveolar milieu were investigated. Firstly, we hypothesised that there may be a defect in type II cell secretion induced by the disease process and evaluated the effects of the lavage fluid of these patients on the epithelial type II cell secretion, which was unchanged by the bronchoalveolar lavage fluid from the other groups. Secondly, we observed an increased proliferation capacity of the lavage fluid from the patients with silicosis for epithelial type II cells, ${ }^{14}$ which may explain the comparative hypertrophy and hyperplasia of type II cells in silicosis but not the low values of phospholipid in the silicosis groups.

Alternative mechanisms for the reduced phospholipids in bronchoalveolar lavage fluid could be related to altered rates of degradation, clearance, or translocation of the phospholipids in the fluid. Whereas altered clearance or translocation cannot currently be verified properly from the methods, they have some support. Firstly, silica particles in the bronchoalveolar milieu are known to be translocated rapidly to the interstitial space. ${ }^{26}$ Secondly, phospholipids act as contact inhibitors against the toxicity of silica ${ }^{27}$ and could also interact with immune complexes in the bronchoalveolar fluid of patients with idiopathic pulmonary fibrosis ${ }^{28}$ and be translocated rapidly in the interstitial space. Thirdly, the presence of "foreign" material in the alveolar space may accelerate the rate of clearance of these materials ${ }^{29}$ and associated lipids. Fourthly, within the whole lung the phospholipids accumulated by the disease process associated with silica exposure are known to be deposited largely (in association or not with the silica particles) in the silicotic nodules, ${ }^{8}$ which may accelerate the translocation of the phospholipids in bronchoalveolar lavage fluid to these sites. Finally, the lipid and protein components of surfactant have multiple roles, ${ }^{30}$ particularly in the repair process, protecting against the potentially damaging effects of proteases and oxidants released in chronic inflammatory states.
Clearly, the changes in phospholipids in bronchoalveolar lavage fluid that are associated with disease are the result of complex multifaceted inflammation-damage-repair processes.

In conclusion, we have confirmed the low values of phospholipids of surfactant in lung lavage fluid in patients with idiopathic pulmonary fibrosis and documented the absence of influence of the fluid on the secretion and proliferation of epithelial type II cells. In patients with silicosis we found depressed concentrations of phospholipids of surfactant and the absence of changes in type II cell secretion capacity. These changes are inherent to the inflammation-damage-repair process.

This study was supported by MRC Canada.

1 Hallman M, Spragg R, Harrell JH, Moser KM, Gluck L. Evidence of lung surfactant abnormality in respiratory failure: study of bronchoalveolar lavage phospholipids, surface activity, phospholipase activity, and plasma myoinositol. f Clin Invest 1982;70:673-83.

2 Robinson PC, Watters LC, King TE, Mason RJ. Idiopathic pulmonary fibrosis. Abnormalities in bronchoalveolar lavage fluid phospholipids. Am Rev Respir Dis 1988;137:585-91.

3 Hughes DA, Haslam PL. Changes in phosphatidylglycerol in bronchoalveolar lavage fluids from patients with cryptogenic fibrosing alveolitis. Chest 1989;95:82-9.

4 Heppleston AG, Fletcher K, Wyatt I. Abnormalities of lung lipids following inhalation of quartz. Experientia 1972;28:938-9.

5 Bégin R, Possmayer F, Ormseth MA, Martel M, Cantin A, Massé S. Effect of aluminum inhalation on alveolar phospholipid profiles in experimental silicosis. Lung 1989;167:107-15.

6 Davis GS. Pathogenesis of silicosis: current concepts and hypothesis. Lung 1986;164:139-54.

7 Bégin R, Cantin A, Massé S. Recent advances in the pathogenesis and clinical assessment of mineral dust pneumoconiosis: asbestosis, silicosis and coal pneumoconiosis. Eur Respir f 1992;2:988-1001.

8 Vigliani ER, Pernis B. Immunological factors in the pathogenesis of the hyaline tissue of silicosis. $\mathrm{Br} \mathcal{F}$ Indust Med 1958;15:8-14.

9 Schuyler MR, Gaumer HR, Stankus RP, Kaimal J, Hoffman E, Salvaggio JE. Bronchoalveolar lavage in silicosis: evidence of type II cell hyperplasia. Lung 1980; 157:95-102.

10 Christman JW, Emerson RJ, Graham WGB, Davis GS. Mineral dust and cell recovery from the bronchoalveolar lavage of healthy Vermont granite workers. Am Rev Respir Dis 1985;132:393-9.

11 Calhoun WJ, Christman JW, Ershler WS, Graham WGB, Davis GS. Raised immunuglobulin concentrations in bronchoalveolar lavage fluid of healthy granite workers. Thorax 1986;41:266-73.

12 Bégin R, Cantin A, Bolleau R, Bisson G. Spectrum of alveolitis in quartz-exposed human subjects. Chest 1987; 92:1061-7.

13 Lesur O, Melloni B, Cantin A, Tanswell AK, Beaulieu $\mathrm{J}-\mathrm{F}$, Bégin R. Silica exposure induced cytotoxicity and proliferation activity of type II pneumocytes. Exp Lung Res 1992;18:173-90.

14 Lesur O, Melloni B, Cantin A, Bégin R. Silica-exposed lung fluids have a proliferative activity for type II epithelial cells. A study on human and sheep alveolar fluids. Exp Lung Res 1992;18:633-54.

15 Cantin A, Boileau R, Bégin R. Increased procollagen III aminoterminal peptide-related antigens and fibroblast growth signals in the lungs of patients with idiopathic pulmonary fibrosis. Am Rev Respir Dis 1988;137:572-8.

16 Cantin A, Bégin R, Rola-Pleszcyzynski M, Boileau R. Heterogeneity of bronchoalveolar lavage cellularity in
stage III pulmonary sarcoidosis. Chest $1983 ; 83: 485-6$.

17 Laurent UBG, Tengblad A. Determination of hyaluronate in biological samples by a specific radioassay technique. Anal Biochem 1980;109:386-94.

18 Folch J, Lees M, Sloane-Stanley GH. A simple method for the isolation and purification of total lipids from animal tissues. F Biol Chem 1957;226:497-509.

19 Bartlett G. Phosphorus assay in column chromatography. f Biol Chem 1959;234:466-8.

20 Rouser G, Fleischer S, Yamamoto A. Two dimensional thin layer chromatographic separation of polar lipids and determination of phospholipids by phosphorus 
analysis of spots. Lipids 1970;5:494-6.

21 Rice WR, Whitsett JA. Inhibition of surfactant release from isolated type II cells by compound $48 / 80$. Biochem Biophys Acta 1984;805:261-7.

22 Snedecor GW, Cochran WC. Statistical methods. Ames, Iowa: Iowa State University Press, 1967.

23 Dubois F, Bégin R, Cantin A, Massé S, Martel M, Bilodeau $\mathrm{G}$, et al. Aluminium inhalation reduces silicosis in a sheep model. Am Rev Respir Dis 1988;137: 1172-9.

24 Bégin R, Dufresne A, Cantin A, Possmayer F, Sébastien P. Quartz exposure, retention and early silicosis in sheep. Exp Lung Res 1989;15:409-28.

25 Sébastien P, Bossé J, Dubois F, Bégin R. Effect of aluminum lactate treatment on the alveolar clearance of quartz injected into the sheep tracheal lobe. In LeBouffant L, ed. Silicosis and mixed dust pneumoconiosis.
Colloque INSERM 1987;155:523-8.

26 Brody AR, Roe MW, Evans JN, Davis GS. Deposition and translocation of inhaled silica in rats. Quantification of particles distribution, macrophage participation and function. Lab Invest 1982;47:533-42.

27 Wallace WE, Vallyathan V, Keane MJ, Robinson V. In vitro biologic toxicity of native and surface-modified silica and kaolin. $\mathcal{F}$ Toxicol Environ Health 1985;16:113-6.

28 Dreisin RB, Schwartz MI, Theofilopoulos AN, Stanford RE. Circulating immune complexes in the idiopathic interstitial pneumonias. N Engl ₹ Med 1978;298:353-7.

29 Morrow PE. Clearance kinetics of inhaled particles. In: Brain JD, Proctor DF, Reid LM, eds. Respiratory defense mechanisms. New York: Marcel Dekker, 1977:491-543. 30 Heppleston AG. The role of surfactant in the pulmonary reaction to mineral particles. Int $f$ Exp Pathol 1991 72:599-616. 